\title{
Utilidad del plasma rico en plaquetas en neumología
}

\author{
PATRICIO RIOSECO S.*, VERÓNICA CÉSPEDES S.*, SUSANA MUÑOZ V.*, \\ SERGIO TAPIA Z.* y DANIELA VÁSQUEZ G.*
}

Usefulness of platelet-rich plasma in pneumology

The use of Platelet-rich plasma (PRP) involves a very complex network of molecular effects favoring tissue regeneration, due the presence of multiple mediators and growth factors. There are several communications about its use on the dental implantology field, plastic surgery and orthpedics. Besides, its utility has been suggested on peripheral nerves regeneration after trauma. In this article we present our experience on the use of PRP on acute injury of the respiratory system. We present a clinical series of 8 patients treated with PRP with positive response. Four of them presenting a massive hemoptysis were treated by direct endoscopic instillation of autologous PRP on the site of lesion; an immediate favorable result was obtained in all of them, without recurrence of bleeding on the follow-up period. A fifth case was a HIV seropositive patient with a spontaneous pneumothorax on intersticial pneumonia. He was treated by direct instillation of PRP through a thoracic tube. Full lung reexpansion was achieved within $72 \mathrm{~h}$. Finally two patients with a respiratory fistula and another patient who suffered a traumatic tracheal rupture were treated with PRP endoscopic instillation, all of them with favorable clinical outcome. The use of autologous products as PRP has shown a good performance in all the clinical situations described, proposing it as a potentially very useful technique, particularly when a minimally invasive approach is required.

Key words: Platelet rich plasma, growth factors, tissue regeneration.

\section{Resumen}

El uso de plasma rico en plaquetas (PRP) involucra una compleja red de efectos moleculares que favorecerían la regeneración tisular, dada la presencia en él de múltiples mediadores y factores de crecimiento. Se ha comunicado su uso con éxito en implantología odontológica, cirugía plástica y ortopedia como también se ha sugerido su utilidad en la regeneración de nervios periféricos posterior a trauma. No existe difusión acerca de su uso en patología respiratoria. Comunicamos nuestra experiencia en el uso de PRP en daño agudo del aparato respiratorio. En esta serie de casos, se trataron 4 pacientes con hemoptisis masiva mediante preparación de PRP autólogo previo al procedimiento e instilación vía endoscópica en el sitio del defecto, con buen resultado inmediato y sin recidiva del sangrado al seguimiento; 1 caso de neumotórax espontáneo con infiltrados pulmonares con fracaso del manejo con sonda endopleural (SEP), que resultó ser una neumonía intersticial con quistes pulmonares en un paciente VIH sero-positivo, instilándose PRP por SEP, reexpandiendo el pulmón a las 72 h; 2 pacientes portadores de fístula respiratoria y 1 paciente portador de ruptura traqueal traumática, todos con buena respuesta. El uso de productos autólogos como PRP ha logrado un favorable rendimiento en todas las situaciones clínicas planteadas, lo que lo sitúa como una herramienta con notable potencial de desarrollo particularmente en casos que por sus características particulares requieren de un manejo mínimamente invasivo.

Palabras clave: Plasma rico en plaquetas, factores de crecimiento, regeneración tisular.

* Unidad de Enfermedades Respiratorias, Hospital Las Higueras, Talcahuano, Chile. 


\section{Introducción}

Las plaquetas son elementos anucleados, cuyo citoplasma es rico en gránulos que contienen diversas substancias biológicamente activas. Los gránulos alfa más numerosos y densos, los gránulos delta en cantidad y contenido intermedio y los lambda, con menor densidad y concentración de substancias.

Los gránulos alfa contienen fibrinógeno, inmunoglobulinas y factores de crecimiento (FC). Los gránulos delta, contienen ADP (adenosín difosfato), TPA (activador tisular del plasminógeno) y serotonina y los gránulos lambda, enzimas lisosomales.

Los FC son proteínas que influyen en la reparación y neo formación de tejido blando y óseo. La liberación de éstos en el sitio de lesión por las plaquetas activadas actúa sobre las células que forman los tejidos circundantes iniciándose cambios en la proliferación, diferenciación, síntesis de proteínas y quimiotaxis.

La zona dañada comienza a repararse dentro de los $3 \mathrm{~min}$ en que sucede la degranulación plaquetaria y su acción dura alrededor de 8 días que es aproximadamente el tiempo de vida de las plaquetas.

En la Tabla 1 se muestra los FC de los gránulos alfa y sus acciones. Vemos por ejemplo que el PDGF (factor de crecimiento derivado de plaquetas) tiene una importante función de proliferación celular, quimiotaxis y formación de colágeno y el VEGF (factor de crecimiento endotelial vascular) es muy importante en la angiogénesis y reparación vascular.

Se considera plasma rico en plaquetas a un volumen de plasma autólogo que contiene entre 4 a 8 veces más plaquetas que el plasma normal esto es alrededor de 300.000 a 1.000 .000 de plaquetas por $\mu$ l.

Ya que el PRP incrementa la regeneración ósea, al ser usado junto a injertos de hueso autó- logo, se le utiliza en cirugía ortopédica, otorrinolaringológica, neurocirugía y maxilofacial. Por su capacidad de incrementar la formación de matriz extracelular, se le utiliza en cirugía plástica y cosmética y por su capacidad de incrementar el tejido fibroso, se le utiliza en medicina del deporte para reparar lesiones musculares y tendíneas. Hemos encontrado sólo un reporte de su uso en nuestra especialidad, en el tratamiento de una fístula broncopleural persistente post resección pulmonar, por lo que decidimos comunicar nuestra experiencia con su utilización en patologías graves que requieren de una rápida reparación para preservar la seguridad del paciente. Presentamos a continuación parte de la experiencia que hemos tenido con su uso en nuestro servicio.

\section{Material y Métodos}

En 8 pacientes internados en nuestro hospital o en control ambulatorio en la Unidad de enfermedades respiratorias que estaban siendo tratados por diversas patologías graves que involucraban un daño agudo de alguna de las estructuras del aparato respiratorio, vía aérea, pleura, tejido pulmonar y que con la terapia habitual, no cedían y ponían en peligro la vida, usamos una o más dosis de PRP instilado o inyectado localmente.

Las patologías que aquejaban a nuestros pacientes eran: 4 hemoptisis, 1 neumotórax, 2 fístulas respiratorias y 1 traumática de la tráquea.

\section{Obtención de PRP}

Se toma una muestra de 20 a $40 \mathrm{~mL}$ de sangre venosa del paciente con citrato de sodio y se somete a centrifugación $280 \mathrm{G}$ por 8 min de esta manera se logra separar los elementos sanguíneos en 4 capas: una capa superficial rica en proteínas plasmáticas; una capa intermedia rica en plaquetas, la porción superior con menos cantidad y la inferior el verdadero PRP, una capa blanca donde

Tabla 1. Factores de crecimiento plaquetarios y su acción principal

\begin{tabular}{|c|c|c|c|c|c|}
\hline $\begin{array}{l}\text { Factor de } \\
\text { crecimiento }\end{array}$ & $\begin{array}{c}\text { Proliferación } \\
\text { pre-osteoblastos }\end{array}$ & $\begin{array}{c}\text { Proliferación } \\
\text { fibroblastos }\end{array}$ & Quimiotaxis & $\begin{array}{c}\text { Matriz } \\
\text { extracelular }\end{array}$ & Angiogenesis \\
\hline PDGF & +++ & +++ & ++ & ++ & - \\
\hline TGF & $+/-$ & $+/-$ & ++ & +++ & - \\
\hline EGF & - & +++ & ++ & - & - \\
\hline IGF & +++ & ++ & +++ & +++ & - \\
\hline VEGF & - & - & - & - & +++ \\
\hline
\end{tabular}

PDGF: factor de crecimiento derivado de plaquetas, TGF: factor de crecimiento transformador, EGF: factor de crecimiento epidérmico, IGF: factor de crecimiento insulínico, VEGF: factor de crecimiento endotelial vascular. 
se depositan los leucocitos y una capa basal roja, de glóbulos rojos. Por medio de pipeteo selectivo, se retira la capa de PRP y se activan las plaquetas con cloruro de calcio al $10 \%$ en dosis de $50 \mathrm{~mL}$ por $\mathrm{mL}$ de PRP. El cloruro de calcio transforma la protrombina endógena en trombina la que a su vez determina la transformación del fibrinógeno en una malla de fibrina bajo la cual se agregan las plaquetas, ricas en FC. Se trata de un sistema de preparación de un agregado de plaquetas insertas en una malla de fibrina, PRGF (plasma rico en factores de crecimiento), que suprime el uso de trombina bovina cuya utilización es indispensable cuando se trabaja con los adhesivos de fibrina clásicos y desaparece el riesgo asociado al no introducir ningún componente exógeno al paciente ${ }^{1}$.

Se induce entonces de esta forma la degranulación de los gránulos alfa plaquetarios, con su rico contenido de FC. Este proceso demora alrededor de $8 \mathrm{~min}$ y se puede acelerar aumentando la temperatura. La administración en el paciente puede ser por inyección en el tejido dañado, instilación o pulverización a través de una sonda. Por otra parte, se puede activar in situ las plaquetas y así acelerar el proceso mediante una sonda de doble lumen; a través de uno de sus lúmenes se administra el PRP y a través del segundo, el cloruro de calcio.

\section{Presentación de casos y resultados}

\section{Uso de PRP en hemoptisis}

Definimos operacionalmente hemoptisis grave como aquella que se acompaña de compromiso hemodinámico o respiratorio o que requiere de transfusión, no importando la cuantía de sangre exteriorizada. En la Tabla 2 se presentan los datos de 3 mujeres y 1 varón que ingresan por hemoptisis que cumple con los criterios de gravedad expuestos, de 54 años de edad en promedio, en falla respiratoria con $\mathrm{SaO}_{2}$ de $85,7 \%$ y un hematocrito que cayó en promedio a 32,5\% que estaban por 17 días en tratamiento médico habitual de su hemoptisis sin que esta cediera. En ellos, se decidió instilar por videobroncoscopia, en el segmento bronquial sangrante un promedio de $18,5 \mathrm{~mL}$ de PRP siendo en todos el resultado positivo en el sentido de haber cesado el sangramiento en forma inmediata. En promedio, los pacientes permanecieron hospitalizados 2,2 días posterior al procedimiento y se han controlado a los 208,7 días no registrándose recidiva del sangramiento.

Un caso representativo es el de un paciente portador de EPOC de 58 años de edad, con secuelas de TBC, calcificadas en el lóbulo superior izquierdo que ingresa sangrando activamente (Figura 1).

La videobroncoscopia a los 7 días de estada y terapia habitual muestra que persiste el sangramiento a través de la laringe, con un coágulo cabalgando en la carina y sangramiento activo desde el bronquio fuente izquierdo. Se identifica como origen la língula, se lava y posteriormente se canula en forma selectiva sus segmentarios y se instila localmente $20 \mathrm{~mL}$ de PRP. Al minuto de realizado el procedimiento cesa el sangrado y el paciente es dado de alta a los 2 días (Figura 2 $\mathrm{a}, \mathrm{b}, \mathrm{c}, \mathrm{d})$. No hubo recidiva de la hemoptisis al control a los 70 días.

\section{Uso de PRP en neumotórax}

Un paciente de 22 años de edad que ingresa por una falla respiratoria secundaria a un neumotórax espontáneo masivo derecho, con infiltrado difuso bilateral, se instala un drenaje pleural que a los 3 días no logra expandir el pulmón. A la semana del ingreso, la tomografía axial computada de tórax (TAC) muestra los quistes e infiltrado pulmonar difuso característicos de la infección por $P$. jirovecii (Figura $3 \mathrm{a}, \mathrm{b}, \mathrm{c}$ ). El paciente es portador de VIH.

Al mes de estada, aún hay pérdida importante de aire por la sonda endopleural y el pulmón no expande por completo. Se decide instilar por la

Tabla 2. Uso de plasma rico en plaquetas (PRP) en hemoptisis grave

\begin{tabular}{|lccccccccl|}
\hline Sexo & $\begin{array}{c}\text { Edad } \\
\text { (años) }\end{array}$ & $\begin{array}{c}\mathbf{S a O}_{2} \\
(\mathbf{\%})\end{array}$ & $\begin{array}{c}\text { Hto } \\
\mathbf{( \% )}\end{array}$ & $\begin{array}{c}\text { Días } \\
\text { pre }\end{array}$ & $\begin{array}{c}\text { PRP } \\
(\mathbf{m L})\end{array}$ & Resultado & $\begin{array}{c}\text { Días } \\
\text { post }\end{array}$ & $\begin{array}{c}\text { Control } \\
\text { días }\end{array}$ & Diagnóstico \\
M & 58 & 85 & 36 & 7 & 20 & + & 2 & 70 & TBC secuelar \\
F & 78 & 91 & 35 & 20 & 15 & + & 2 & 370 & Bronquiectasias \\
F & 69 & 80 & 27 & 26 & 20 & + & 2 & 365 & TBC secuelar \\
F & 14 & 87 & 32 & 15 & 20 & + & 3 & 30 & Aspergiloma \\
Promedio & 54 & 85,7 & 32,5 & 17 & 18,5 & + & 2,2 & 208,7 & \\
\hline
\end{tabular}

Hto: hematocrito. Días pre: días pre- instilación de PRP. Días Post: días post-instilación de PRP. 


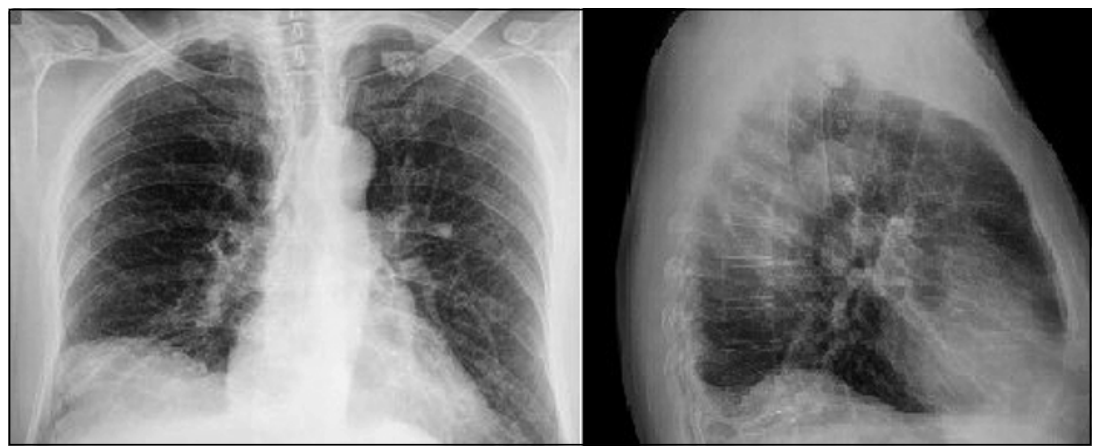

Figura 1. Secuela calcificada en lóbulo superior izquierdo y lobulación diafragmática derecha.
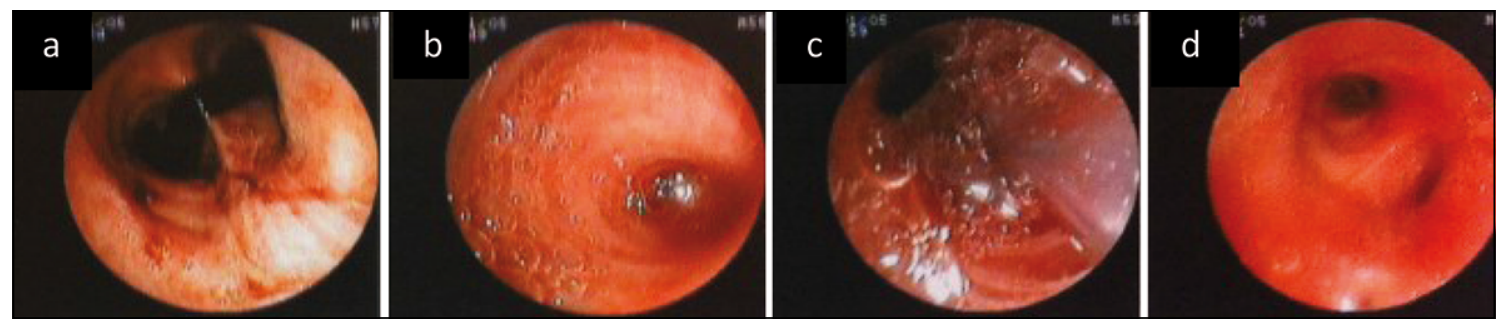

Figura 2. Imágenes broncoscópicas en paciente con hemoptitis; a: Sangramiento activo desde bronquio fuente izquierdo; b: sangramiento lingular; c: instilación de PRP; d: resultado al minuto post instilación.

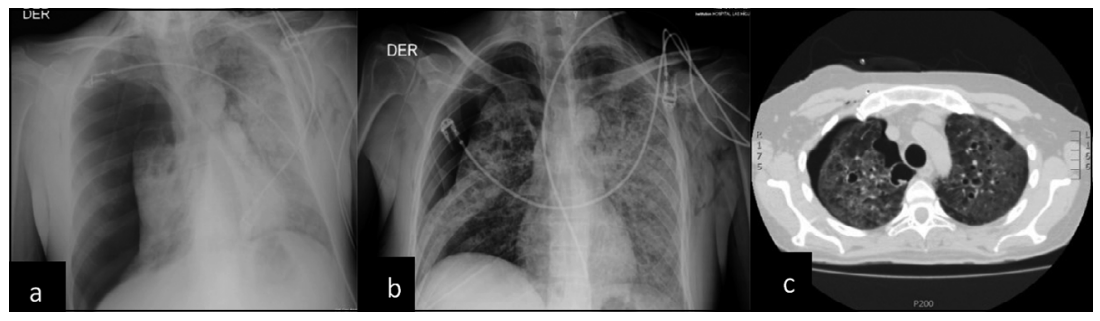

Figura 3. a: radiografía de tórax con neumotórax masivo derecho; b: radiografía de tórax: persistencia de neumotórax al $4^{\circ}$ día; c: TAC de tórax al $7^{\circ}$ día muestra quistes e infiltrado pulmonar difuso.

sonda endopleural $300 \mathrm{~mL}$ de PRP y al tercer día del procedimiento, el pulmón está expandido por completo ya retirado el drenaje y el paciente puede egresar (Figura 4 a y b).

\section{Uso de PRP en cierre de fistulas respiratorias}

Caso 1: Una paciente de 92 años de edad que ingresa por un cuadro catalogado como neumonía comunitaria con expectoración verde que no cede al tratamiento antibiótico. La TAC muestra una cavidad hepática que comunica con el pulmón derecho a través del diafragma. La broncoscopia muestra la tráquea con bilis que proviene del lóbulo medio (LM) desde donde sale material que impresiona como membranas hidatídicas (Figura $5 \mathrm{a}, \mathrm{b}, \mathrm{c})$.

Se decide realizar una técnica mixta, con inyección en corona radiada de alcohol absoluto en los segmentarios de LM y luego, canularlos selectivamente e instilar $20 \mathrm{~mL}$ de PRP. A la semana de realizado el procedimiento, la fístula está sellada y a los controles al mes y al año, la paciente está asintomática (Figura $6 \mathrm{a}, \mathrm{b}, \mathrm{c}$ )

Caso 2: Un paciente de 32 años de edad, portador de VIH, TBC multirresistente que luego de casi un año de estadía en el Servicio, con una SNG para alimentación tose y expectora al intentar deglutir. La videobroncoscopia muestra un orificio fistuloso en la tráquea, casi a nivel del nacimiento del bronquio fuente izquierdo (BFI) cuya superficie se encuentra ya epitelizada. Se le da un trago de azul de metileno, el cual pasa de inmediato a la vía aérea. Se hace el diagnóstico de fístula esófago-traqueal que se comprueba con radiología (Figura $7 \mathrm{a}, \mathrm{b}$ ). Se observa el paso desde el esófago a la tráquea del medio de contraste.

Se identifica el trayecto fistuloso y se procede a escarificar con cepillo con el fin de obtener una superficie cruenta y luego, con sonda de doble lumen se inyecta $30 \mathrm{~mL}$ de PRP que se activa 

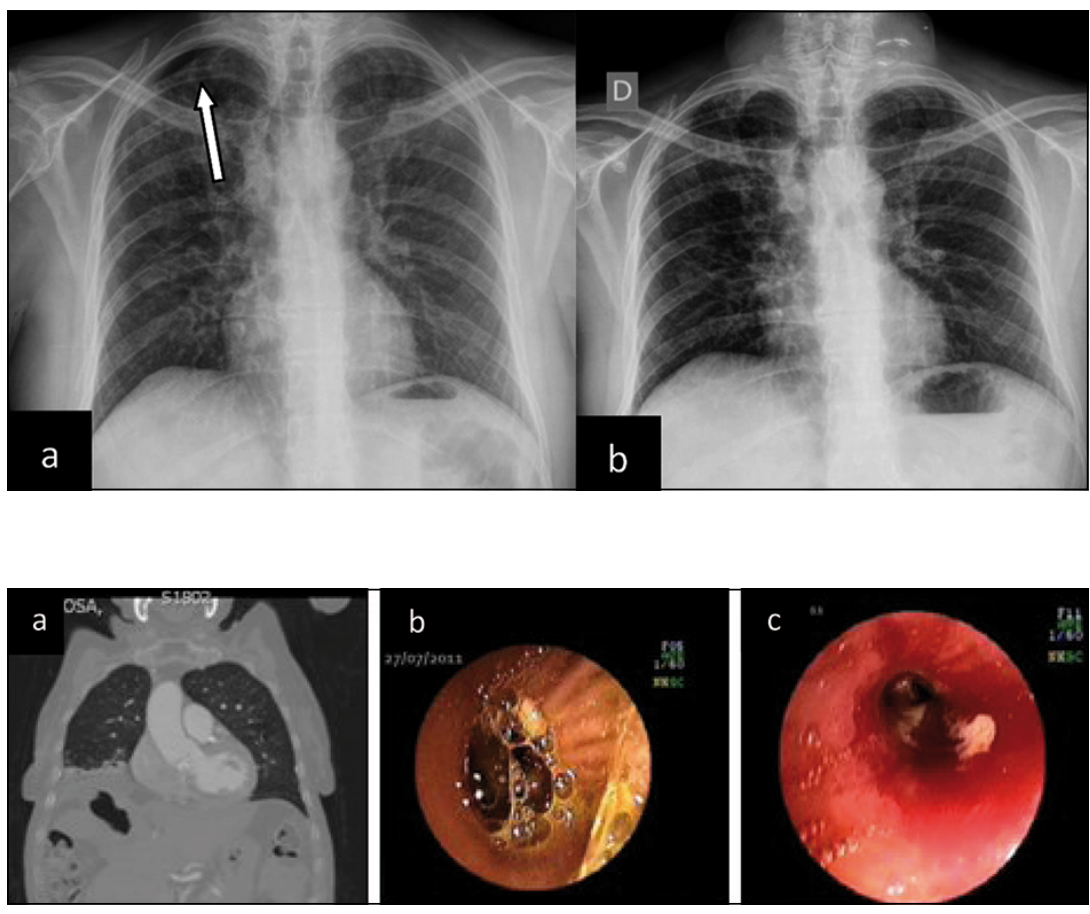

Figura 5. Fístula hepato-pulmonar. a: TAC: comunicación hepatopulmonar; b: Imagen broncoscópica: flujo de bilis desde lóbulo medio; c: Imagen broncoscópica de membranas hidatídicas.
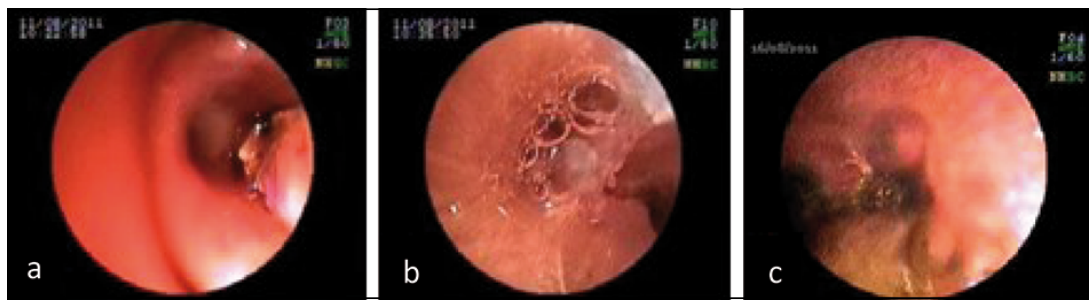

Figura 6. a: inyección de etanol absoluto; b: instilación de PRP; c: fístula sellada al $7^{\circ}$ día de PRP.
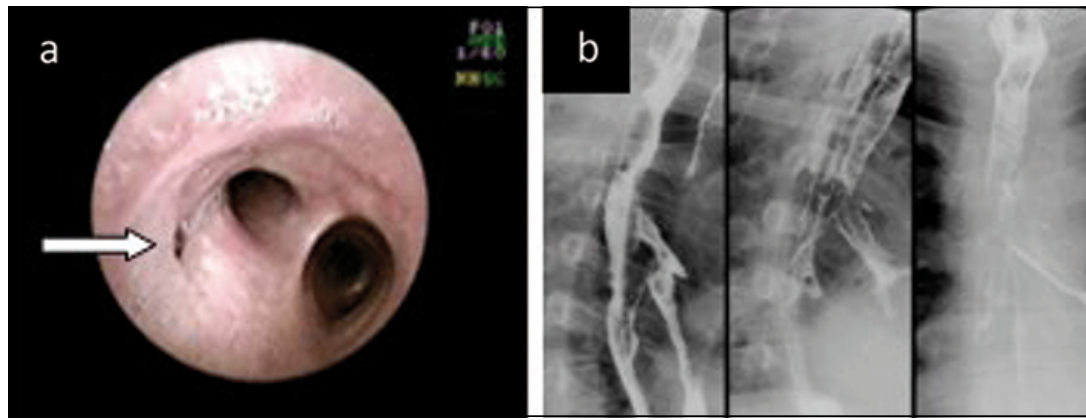

Figura 7. Fístula esófagotraqueal. a: imagen broncoscópica muestra orificio fistuloso sobre la carina (flecha); b: estudio radiológico: paso del medio de contraste desde el esófago a la tráquea.

localmente con cloruro de calcio. A la semana del procedimiento, el orificio de la fístula está cerrado con tejido de granulación y la radiología muestra un trayecto fistuloso esofágico que no se abre a la vía aérea (Figura $8 \mathrm{a}, \mathrm{b}, \mathrm{c}$ ). El paciente es dado de alta a los 355 días de estadía. Lamentablemente, el paciente no siguió ni las indicaciones dietéticas ni el tratamiento anti TBC reingresando a los 4 meses con baciloscopias +++ y la fístula nuevamente activa. Se le instaló una prótesis endoesofágica con el fin de paliar los efectos de la fístula y en un segundo tiempo, hacer en forma complementaria un nuevo tratamiento endoscópico.

\section{Uso de PRP en ruptura traumática de tráquea}

Finalmente presentamos una paciente de 52 años de edad, obesa mórbida que ingresa en falla respiratoria grave secundaria a una neumonía 

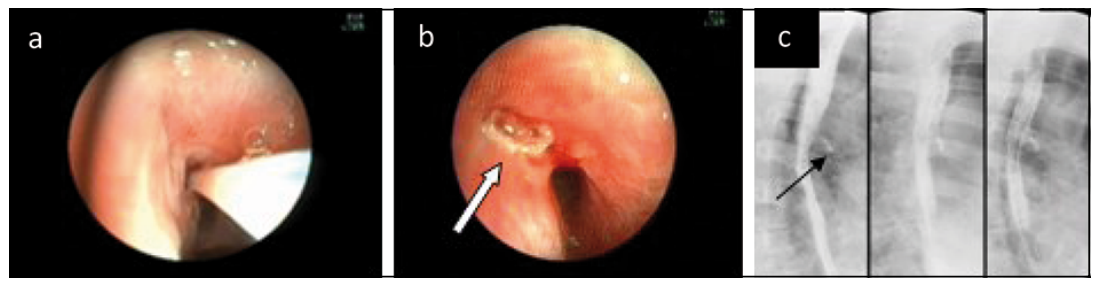

Figura 8. Evolución de la fístula esófago-traqueal con la aplicación de PRP. Imágenes broncoscópicas muestran: a: escarificación e instilación de PRP y b: tejido de granulación; c: estudio radiológico: fístula cerrada hacia la tráquea (flecha).
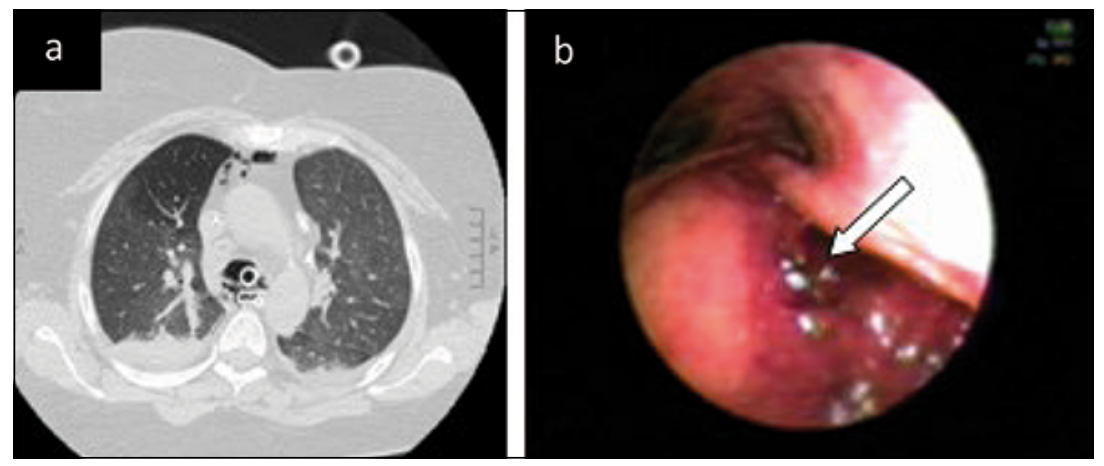

Figura 9. Ruptura traumática de la tráquea. a: TAC: muestra paso de aire desde la tráquea al mediastino; b: imagen broncoscópica: ruptura precarinal de la pared posterior de la tráquea.
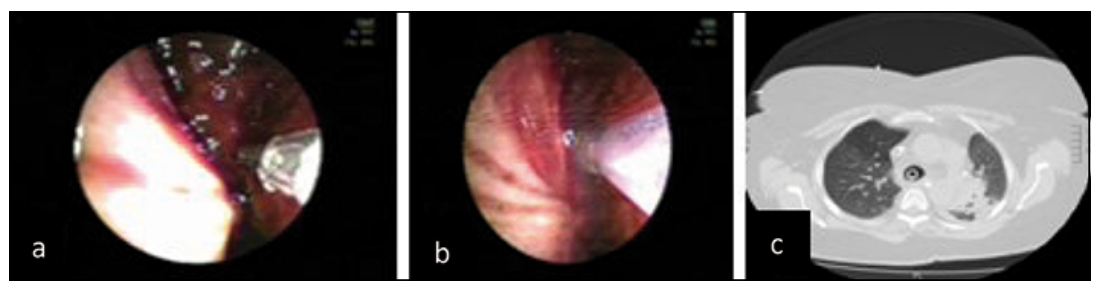

Figura 10. Ruptura traumática de la tráquea. Imágenes broncoscópicas a y b: inyección de PRP en los labios de la herida traqueal; c: TAC muestra que no hay paso de aire al mediastino.
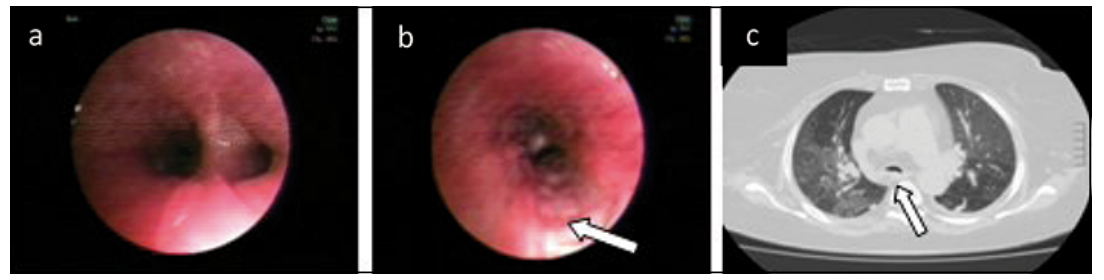

Figura 11. a: control al $7^{\circ}$ día; b: zona de cicatriz traqueal (flecha); c: cicatriz en la pared posterior de la tráquea (flecha).

adquirida en la comunidad. Requiere intubación endotraqueal la cual es dificultosa. De inmediato luego de la conexión a ventilación mecánica aparece enfisema subcutáneo en la región cervical. La TAC muestra una pérdida de continuidad de la pared traqueal posterior con fuga de aire hacia el mediastino. La videobroncoscopia demuestra una extensa rotura de la pared membranosa de la tráquea precarinal, de más o menos $4 \mathrm{~cm}$ de longitud (Figura 9 a y b).

Se decide tratar localmente con PRP, inyectando $30 \mathrm{~mL}$ en los labios de la herida activando las plaquetas in situ con una sonda de doble lumen. Al día siguiente en la TAC ya no se demuestra el paso de aire hacia el mediastino. A la semana, el control endoscópico muestra una capa de fibrina en el sitio de la lesión original y una cicatriz subyacente (Figura $10 \mathrm{a}, \mathrm{b}, \mathrm{c}$ ). La paciente es extubada. La TAC a la semana post-extubación muestra una zona cicatricial en el sitio intervenido. La paciente se controló al mes, sin problemas (Figura $11 \mathrm{a}, \mathrm{b}, \mathrm{c}$ ).

\section{Discusión}

La ortobiología es una ciencia relativamente nueva que se basa en desarrollar tratamientos destinados a mejorar las habilidades innatas del 
organismo para repararse y regenerarse aplicando materiales provenientes de fuentes biológicas (biomateriales) lo que ha constituido un gran avance dentro del contexto de la medicina regenerativa especialmente en las lesiones del aparato locomotor. Ejemplos de esto son la utilización de células madre, uso de factores de crecimiento y de substancias viscolelásticas que ofrecen posibilidades reales para acelerar los procesos normales de reparación de tejidos óseos y blandos ${ }^{1}$. La utilización de plasma rico en plaquetas en diversos escenarios quirúrgicos va dirigida a obtener esos fines.

La primera comunicación del uso de plasma autólogo rico en plaquetas la hacen Ferrari y cols., en 1987 quienes en 15 cirugías a corazón abierto, ahorran transfusiones de sangre homóloga al re-infundir durante las mismas plasma rico en plaquetas obtenido previo al ingreso a bomba de circulación extracorpórea y lo que es muy interesante, de manera intercurrente, demuestran también una menor incidencia de infecciones en estos pacientes ${ }^{2}$.

Posteriormente y en especial desde los años ' 90 en adelante se ha desatado una tendencia en el uso de productos autólogos con el fin de optimizar los procesos de reparación en un gran número de aplicaciones. En el año 1997. Whitman y cols., inician la era de la aplicación de PRP en la cirugía maxilofacial comunicando su utilidad en la regeneración de tejido blando y óseo ${ }^{3}$, expandiéndose desde entonces su utilización, pero sin que haya hasta el momento estudios clínicos randomizados controlados en seres humanos con un gran número de pacientes que apoyen su utilización. Lo que se encuentra en la literatura son comunicaciones de casos o series de casos con un número reducido de individuos especialmente en el terreno de la cirugía traumatológica, maxilofacial, dental y plástica y cosmética ${ }^{5-10}$.

Sin embargo, su uso parece tener potentes bases fisiopatológicas. En una muestra de sangre normal, encontramos un $93 \%$ de glóbulos rojos, un $6 \%$ de plaquetas y un $1 \%$ de glóbulos blancos. Activadas por la trombina, las plaquetas emiten pseudópodos, cambian de forma y se agregan sobre el tejido dañado. Las plaquetas mediante este mecanismo, son las responsables de la hemostasis pero también, gracias a su riqueza en factores de crecimiento, son responsables de la neoformación de tejido conectivo y neoangiogénesis.

Como vimos en la introducción, los factores de crecimiento más importantes presentes en los gránulos alfa de las plaquetas son el Factor de crecimiento transformador beta (TGF-B), el factor de crecimiento derivado de plaquetas $A B$ y BB (PDGF AB-BB), el factor de crecimiento insulínico (IGF), el factor de crecimiento del endotelio vascular (VEGF), el factor de crecimiento epidérmico (EGF) y el factor de crecimiento de fibroblastos (FGF). Los dos primeros estimulan la producción de células mesenquimáticas y son responsables de formación de matriz extracelular incluyendo tejido colágeno. Su presencia en el sitio de lesión estabiliza la herida y dirige la migración y división de las células mesenquemáticas y epiteliales locales lo que lleva a la formación de una cicatriz estable. El VEGF y el FGF-2 son importantes en la neo angiogénesis por lo que favorecen el aporte de nutrientes, células progenitoras y neutrófilos al sitio de injuria influyendo de esta manera en el desarrollo y la defensa del tejido nuevo en formación y el FGF beta es importante en la supresión del sistema inmune. Es dable pensar que de esta manera, la aplicación local de PRP en heridas y úlceras crónicas, a menudo infectadas sea efectiva como también, la menor incidencia de infecciones con su uso, en cirugía cardiovascular ${ }^{2}$. En teoría, si aumentamos muchas veces la concentración de estos factores en un sitio dado, el efecto generador de tejido nuevo también se verá multiplicado. La idea que subyace a la preparación de PRP es la de revertir la relación glóbulos rojos/plaquetas en la sangre, disminuyendo la cantidad de eritrocitos a un 5\% y concentrando las plaquetas a un $94 \%$. Se ha demostrado que el aumento de concentración de plaquetas en el PRP para que sea efectivo, debe ser al menos de $1.000 \times 10^{6} / \mathrm{mL}$ de plasma ya que cantidades menores disminuyen su eficacia y por otro lado, cantidades mayores no aumentan significativamente su efecto ${ }^{11,12}$.

La pregunta que cabe hacer es si los métodos de obtención de PRP logran realmente esa concentración de plaquetas por un lado y por otra parte si estas exhiben la concentración de factores de crecimiento que se preconiza como útiles. A este respecto, Jeon Woo Lee et al en un interesante trabajo obtienen de voluntarios sanos jóvenes muestras que separan en 4 grupos; sangre total inactivada; PRP inactivado, sangre total activada y PRP activado y concluyen que efectivamente se logra una concentración de plaquetas alrededor de 5 veces la cantidad en la sangre total; el PDGF-AB es 8,28 veces mayor en el PRP que en la sangre total; el PDGF $\mathrm{BB}$ es 9,12 veces mayor en el PRP que en la sangre total no habiendo diferencia estadística significativa en las cantidades de estos factores de crecimiento al comparar PRP no activado $v s$ PRP activado. TGF-beta resultó ser 2,55 veces más en el PRP que en la sangre total por lo que 
la respuesta a la interrogante planteada es que con los métodos de preparación de PRP en uso, logramos una concentración de plaquetas y de factores de crecimiento útiles en el control del crecimiento celular, estimulación de matriz extracelular y supresión del sistema inmune es decir, una gran cantidad de substancias potencialmente terapéuticas fueron detectados y liberados por las plaquetas en preparaciones autólogas de PRP lo que puede ser de enorme utilidad en nuestra práctica clínica ${ }^{13,14}$

La hemoptisis masiva y/o persistente es una emergencia médica que amenaza la vida del paciente. La embolización selectiva de las arterias bronquiales se ha convertido en el tratamiento no quirúrgico de elección en estos casos ${ }^{15,16}$, sin embargo, no en todas partes se cuenta con el equipamiento ni la experiencia necesaria para la realización de un angiografía intervencionista y por lo tanto, es necesario disponer de otros métodos menos invasivos pero eficaces que estén al alcance del neumólogo que trabaja en centros de menor complejidad.

De acuerdo a lo publicado, casi un $28 \%$ de los especialistas en enfermedades respiratorias, presencian algún caso de muerte por hemoptisis en un período de tiempo de un año de modo que es aún una entidad frecuente sobre todo en medios donde la TBC o sus secuelas se ven en un número importante de pacientes ${ }^{17}$.

Pensamos que el uso de PRP en forma local es una alternativa válida en el tratamiento de una hemoptisis grave. Teníamos experiencia previa en el tratamiento de hemoptisis severa con adhesivos de fibrina con resultados similares a lo que hemos obtenido con el uso de $\mathrm{PRP}^{18}$, sin embargo, el uso de un material autólogo se debe considerar como una mejor alternativa ya que al no tener que usar fibrina bovina ni fibrinógeno obtenido a partir de múltiples donantes, como es en el caso de los adhesivos de fibrina disponibles se obvia el riesgo de manifestaciones de hipersensibilidad y el de la transmisión de enfermedades infecciosas (VIH; Hepatitis) $^{19-22}$.

El resultado obtenido, puede ser considerado como definitivo o como un puente mientras se define la terapia definitiva como en el caso de nuestra paciente con un aspergiloma, que luego de un mes fue intervenida sin el riesgo que conlleva una cirugía de urgencia en un sujeto anémico y en falla respiratoria.

El tratamiento del neumotórax masivo es la descompresión mediante la instalación de una sonda endopleural. En el caso de un neumotórax espontáneo secundario como en nuestro paciente, este debe ir seguido del manejo definitivo de su patología una vez conseguida la reexpansión del pulmón. En estos casos es frecuente la mantención de la fuga aérea pero luego de 4 a 7 días, se debe considerar medidas más agresivas.

Entre un 2 a un 5\% de pacientes con neumonía por Pneumocistis jirovecii hacen neumotórax, complicación grave ya que la mortalidad puede llegar en algunas series entre 32 y $50 \%$

Dado que la recidiva es frecuente, la necesidad de cirugía es de alrededor del 32\% la internación en UCI de un $42 \%$ y la mortalidad de la intervención es elevada llegando a un $32 \%{ }^{23}$.

Entre las técnicas quirúrgicas usadas, está la pleurodesis realizada a través de VATS (videotoracoscopia), que habitualmente requiere de anestesia general, en un paciente grave e hipoxémico lo cual aumenta la morbimortalidad ${ }^{23,24}$. Creemos que el tratamiento conservador con PRP a través de la sonda endopleural puede resultar definitivo en algunos casos seleccionados en los que el tratamiento médico de la condición de base mejorará al paciente o puede dar tiempo para mejorar las condiciones generales del enfermo para en un segundo tiempo ir a la solución definitiva, sin el riesgo de sobreinfección que conlleva la mantención por largo tiempo del drenaje pleural en un paciente inmunosuprimido.

El tratamiento de las fístulas biliorespiratorias es tradicionalmente quirúrgico, con el drenaje de la colección subdiafragmática, resección del trayecto fistuloso y resección o no del segmento pulmonar comprometido. Sin embargo, se trata de una gran cirugía con post operatorio tormentoso. En el último tiempo, se prefiere la colocación endoscópica de stents en la vía biliar para disminuir la presión, unido al drenaje de las colecciones pleural y subdiafragmática como un manejo menos agresivo. Sin embargo, esta conducta involucra largos períodos de hospitalización, con un resultado no definitivo ya que en la gran mayoría de los casos se debe en un segundo tiempo ir a la resección del trayecto fistuloso. Dentro de las posibilidades terapéuticas no quirúrgicas se encuentran la colocación de endoprótesis biliares metálicas o plásticas y la embolización del trayecto fistuloso. Sin embargo, existe poca experiencia con estos métodos y algunos expertos recomiendan sólo la colocación de endoprótesis como tratamiento exclusivo cuando el paciente tiene una enfermedad neoplásica o una expectativa de vida baja ${ }^{24}$.

En un paciente añoso, cualquiera de las opciones significa un riesgo mayor por lo que en nuestro caso, optamos por una conducta mínimamente invasiva con un resultado que fue inmediatamente favorable demostrándose además la persisten- 
cia del efecto a un año plazo hecho que habla de la eficaz acción regenerativa de tejidos del PRP.

Por su parte, las fístulas esofagotraqueales benignas son raras $\mathrm{y}$, en nuestro paciente tanto la TBC pulmonar como el largo tiempo de intubación esofágica son condiciones que podrían llevar a una inflamación crónica necrotizante de la pared traqueal en el primer caso o de la pared esofágica en el segundo caso causando la comunicación esófago traqueal. La cirugía es la terapia de elección, pero las condiciones del paciente: desnutrición severa, TBC MDR (multidrogoresistente) y HIV no hacían recomendable esa conducta. El tratamiento local con PRP demostró la capacidad de regeneración tisular rápida y adecuada ya que a la semana, el tejido de granulación obstruía el extremo traqueal. Es probable que con un enfrentamiento similar desde el lado esofágico, el trayecto fistuloso se hubiera ocluido por completo y la fístula no se hubiera reactivado luego del alta. Por otra parte, los métodos endoscópicos que hasta el momento han probado ser efectivos en el tratamiento de fístulas bronquiales, lo han sido siempre que el defecto no tenga un diámetro mayor a $3 \mathrm{~mm}^{25-29}$. En nuestra experiencia con PRP, los diámetros de las fístulas tratadas fueron mucho mayores que este límite con un resultado favorable. La misma capacidad de reparación tisular que vimos en el tratamiento de fístulas quedó demostrada claramente en el caso de la rotura traumática de la pared posterior de la tráquea. Como pudimos apreciar, al día siguiente de la intervención local ya no había pérdida de aire hacia el mediastino lo que habla del comienzo inmediato de la acción de los factores de crecimiento presentes en el PRP y su capacidad efectiva de cicatrización a la semana del procedimiento. La rotura traqueal secundaria a intubación es un cuadro poco frecuente pero que conlleva un alto riesgo de morbimortalidad. La intubación de urgencia como en nuestra paciente es el principal factor de riesgo y aumenta tres veces la mortalidad, al compararla con la intubación electiva; su manejo no está claramente definido, pero en la actualidad se preconiza que debe ser conservador ya que el abordaje quirúrgico conlleva más complicaciones que beneficios y consiste fundamentalmente en esperar que el propio organismo lleve a cabo los procesos de reparación de la lesión. Se intenta que el extremo distal del tubo endotraqueal permanezca varios centímetros por delante de la zona dañada y mantener una actitud expectante hasta que la herida cierre por sí misma, lo cual lleva un tiempo no bien definido con el riesgo siempre presente de la mediastinitis, cuadro de difícil manejo y alta mor- talidad $^{30,31}$. Con el uso local de PRP, se logra un efecto más rápido y definitivo ya que se aceleran dichos procesos de curación.

\section{Conclusiones}

El resultado obtenido en los casos presentados, nos permite concluir que el PRP es técnicamente fácil de obtener y por lo tanto ampliamente accesible, que podemos manejar la rapidez en la formación del coágulo, es barato al compararlo con los adhesivos de fibrina clásicos y no tiene los riesgos de estos para el paciente ya que es autólogo. Puede ser un tratamiento definitivo, acorta el tiempo de estadía hospitalaria y abre una ventana hacia su utilización en otras patologías como por ejemplo, en la reducción biológica de volumen pulmonar en casos de enfisema pulmonar de los lóbulos superiores.

\section{Bibliografía}

1.- REYES M, MONTERO S, CIFUENTES J F, ZARZAR E. Actualización de la técnica de obtención y uso del plasma rico en factores de crecimiento (PRGF). Revista Dental de Chile 2002; 93: 25-8.

2.- FERRARI M, ZIA S, VALBONESI M, HENRIQUET F, VENERE G, SPAGNOLO S, et al. A new technique for hemodilution, preparatio of autologous platelet-rich plasma and intraoperative blood salvage in cardiac surgery. Int J Artif Organs 1987; 10: 47-50.

3.- WHITMAN D H, BERRY R L,GREEN D M. Platelet gel: an autologous alternative to fibrin glue with applications in oral maxillofacial surgery. J Oral Maxillofac Surg 1997; 55: 1294-9.

4.- GARDNER M J, DEMETRAKOPOULOS D, KLEPCHICK P R. The efficacy of autologous platelet gel in pain control and blood loss in total knee arthroplasty. An analysis of the haemoglobin, narcotic requirement and range of motion. Int Orthop 2007; 31: 309-13.

5.- SIEBRECHT M A, DE ROOIJ P P, ARM D M. Platelet concentrate increases bone ingrowth into porous hydroxyapatite. Orthopedics 2002; 25: 169-72.

6.- BIBBO C, BONO C M, LIN S S. Union rates using autologous platelet concentrate alone and with bone graft in high-risk foot and ankle surgery patients. J Surg Orthop Adv 2005; 14: 1-6.

7.- BHANOT S, ALEX J C. Current applications of platelet gels in facial plastic surgery. Facial Plast Surg 2002; 18 : 27-33.

8.- MARX R E, CARLSON E R, EICHSTAEDT R M. Platelet rich plasma:Growth factor enhacement for bone grafts". Oral Surg Oral Med Oral Pathol Oral Radiol Endod 1998; 85: 638-46. 
9.- GONZÁLEZ M, ARTEAGA-VIZCAÍNO M A, BENITO M. Aplicación del plasma rico en plaquetas (PRP) y sus derivados en implantología dental y cirugía plástica. Invest Clin 2012; 53: 408-18.

10.- MARX R E. Platelet rich plasma (PRP): what is PRP and what is not PRP? Implant Dent 2001; 10: 225-8.

11.- ROBINDER S D, SCHWARTZ E M, MALONEY M. Platelet rich plasma therapy- future or trend? Arthritis Res Ther 2012; 14: 219-31. DOI: 10.1186/ar3914.

12.- LEE J W, KWON O H, KIM T K, CHO Y K, CHOI K Y, CHUNG H Y, et al. Platelet rich plasma: Quantitative assessment of growth factor levels and comparative analysis of activated an inactivated groups. Arch Plast Surg 2013; 40: 530-5.

13.- PIETRZAK W S, EPPLEY B L. Platelet rich plasma: biology and new technology. J Craniofac Surg 2005; 16 : 1043-54.

14.- EPPLEY B L, WOODELL J E, HIGGINS J. Platelet quantification and growth factor analysis from plateletrich plasma: implications for wound healing. Plast Reconstr Surg 2004; 114: 1502-8.

15.- WOO S, YOON C J, CHUNG J W, KANG S G, JAE $\mathrm{H} \mathrm{J}, \mathrm{KIM} \mathrm{H} \mathrm{C}$, et al. Bronchial artery embolization to control Hemoptysis:Comparison of N-Butyl-2-Cyanoacrylate and Polyvinyl Alcohol Particles. Radiology 2013; 269: 594-602.

16.- DE GREGORIO M A, MEDRANO J, MAINAR A, ALFONSO E R, RENGEL M. Tratamiento endovascular mediante embolizaciòn arterial bronquial en la hemoptisis masiva. Seguimiento a corto y largo plazo durante 15 años. Arch Bronconeumol 2006; 42: 49-56. DOI: $10.1157 / 13084394$.

17.- HAPONIK E F, FEIN A, CHIN R. Managing lifethreatening hemoptysis:has anything really changed? Chest 2000; 118: 1431-5.

18.- RIOSECO P. Fibrin adhesives in the emergency management of moderate to severe hemoptysis. Eur Respir J 1996 Suppl; 23: 58S. (Abstract P416) European Respiratory Society Annual Congress, Stockholm, 1996.

19.- WILSON S M, PELL P, DONEGAN E A. HIV-1 transmission following the use of cryoprecipitate fibrinogen as gel/adhesive. Transfusion 1991; 31: S51.

20.- HINO M, ISHIKO O, HONDA K I, YAMANE T, OHTA K, TAKUBO T, et al. Transmission of symptomatic parvovirus B19 infection by fibrin sealant used during surgery". Br J Haematol 2000; 108: 194-5.
21.- TABÉLÉ C, MONTANA M, CURTI M, TERME T, RATHELOT P, GENSOLLEN S, et al. Organic glues or fibrin glues from pooled plasma: efficacy, safety and potential as scaffold delivery systems. J Pharm Pharm Sci 2012; 15: 124-40.

22.- RIVAS DE ANDRÉS J, JIMÉNEZ LÓPEZ M F, LÓPEZ-RODÓ L M, PÉREZ TRULLEN A, TORRES LANZAS J. Normativa sobre el diagnóstico y tratamiento del neumotórax espontáneo. Arch Bronconeumol 2008; 44: 437-48. DOI: 10.1016/S0300-2896(08)721082.

23.- MARÍN PÉREZ A L, TOLEDO SANTANAN, MARÍN HERNÁNDEZ A, ALONSO DOMÍNGUEZ N, CONCEPCIÓN O A, MARÍN TOLEDO I. Neumotórax en pacientes con SIDA. Actualización sobre el tema. Rev Méd Electrón. [Seriada en línea] 2010; 32 (4). Disponible en URL:http://www.revmatanzas.sld.cu/revista\%20 medica/ano\%202010/vol4\%202010/tema01.htm.

24.- LESLIE J M, GALLANT J E, CHAISSON R E. Pneumothorax in patients with AIDS. Infect Dis Clin Prac 1992; 1: 308-13.

25.- TAKAOKA K, INOUE S, OHIRA S. Central bronchopleural fistulas closed by bronchoscopic injection of absolute ethanol. Chest 2002; 122: 374-8.

26.- DE GIACOMO T, FRANCIONI F, VENUTA F, RENDINA E A, RICCI C. Benign esophageal-respiratory fistulae. The surgical treatment and results of 10 cases. Minerva Chir 1993; 48: 311-6.

27.- LIN J, IANNETTONI M D. Closure of bronchopleural fistulas using albumin-glutaraldehyde tissue adhesive. Ann Thorac Surg 2004; 77: 326-8.

28.- PRADO F, BOZA M L, ISAMITT D. Bronchopleural fistula in children. Treatment with endoscopic sealing. Eur Respir J 2002; 20 (Suppl): 149 (Abstract) 12th ERS Annual Congress. September 2002.

29.- PRADO A F. Cierre efectivo por vía broncoscópica de fístula broncopleural de alto flujo en paciente con síndrome de distress respiratorio agudo grave. Rev Chil Pediatr 2006; 77: 501-5.

30.- ATHANASSIADI K A. Infections of the mediastinum. Thorac Surg Clin 2009; 19: 37-45.

31.- MIÑAMBRES E, BURÓN J, BALLESTEROS M A, LLORCA J, MUÑOZ P, GONZÁLEZ-CASTRO A. Tracheal rupture after endotracheal intubation: a literature systematic review. Eur J Cardiothor Surg 2009; 35 : 1056-62.

Correspondencia a:

Dr. Patricio Rioseco S.

Servicio de Medicina, Hospital Las Higueras.

Talcahuano, VIII Región.

Email: parioseco@gmail.com 